\title{
EL IMPACTO DE LO RELIGIOSO SOBRE LA PRÁCTICA POLIITICA EN MARRUECOS: EL CASO DE LA ALTERNANCIA*
}

\section{THE IMPACT OF THE RELIGIOUS ORDER ON THE POLITICAL PRACTICE IN MOROCCO: THE CASE OF THE ALTERNATION}

\author{
M. Fouad El Achouri \\ Universidad Moulay Ismael de Meknes \\ fouadelachouri@gmail.com
}

Recibido: octubre de 2018

Aceptado: noviembre de 2018

Palabras clave: Hassan II, Alternancia, Religión, Legitimidad, Particularismo, Consenso, Partidos políticos. Keywords: Hassan II, Alternation, Religious Legitimacy, Particularism, Consensus, Political Parties.

Resumen: La cultura del consenso, peculiaridad propia de la cultura política marroquí fruto de la conciliación entre dos tipos de legitimidades diametralmente opuestas (religiosa y laica), va a dar a los diferentes conceptos e instrumentos de la práctica política y del ejercicio del poder una connotación propia y singular en relación con los conocidos conceptos tanto en ciencia política y en derecho constitucional por un lado, como en la práctica política de los países occidentales del otro: separación de poderes, monarquía parlamentaria, constitución, partidos políticos, elecciones, oposición... etc. La alternancia de su lado no escapará a esta norma fundadora de la especificidad de la excepción marroquí.

Abstract: The culture of consensus, a particularity specific to the Moroccan political culture resulting from the conciliation between two diametrically opposed types of legitimacy (religious and secular), will give the different concepts and tools of political practice and the exercise of power a genuine and unique connotation compared to that known both in political science and constitutional law on the one hand, and in the political practice of Western countries on the other: separation of powers, parliamentary monarchy, constitution, political parties, elections, opposition ... etc. Alternation, as well will not escape from this founding rule on which the specificity of the Moroccan exception is based.

(*) Traducción de Abdelhamid Adnane, coordinador del monográfico. 


\section{Introducción}

La alternancia es uno de los aspectos más importantes de la democracia. Permite al pueblo, a la vez origen y finalidad de poder, cambiar de política confiándole su destino a una nueva mayoría a través de las urnas. Este concepto, que hace del criterio numérico una de sus bases fundadoras, toma una connotación particular en Marruecos dónde el Islam es, por excelencia, el cimiento de la cultura política marroquí.

Antes de proceder al estudio de la alternancia en Marruecos (epígrafe 2), y para abordar mejor y comprender el contenido de la iniciativa real relativa al particularismo marroquí en este campo tan delicado como espinoso, en cuanto afecta a uno de los pilares fundamentales de la democracia, a saber la soberanía popular fuente de toda legitimidad del poder, nos parece de suma importancia exponer las diferentes dimensiones de la democracia (epígrafe 1).

\section{Las diferentes dimensiones de la democracia}

Podemos distinguir entre tres dimensiones: la dimensión política (1.1), la dimensión social (1.2), y la dimensión cultural (1.3).

\section{I La dimensión política}

Las elecciones, así como las medidas y los procedimientos técnicos que las rodean, son sin duda alguna el instrumento más importante de la democracia política, que le otorga a la mayoría el derecho a imponer sus preferencias y sus opciones. El pueblo soberano, por el juego de la alternancia, obliga los partidos políticos a tener en cuenta sus necesidades y sus demandas. Los partidos políticos, conscientes de que es su futuro el que está en juego, están obligados a respetar los proyectos para los cuales han sido elegidos.

De este modo, "la démocratie possède, par sa valeur humaine et éthique, une valeur éminemment pragmatique. Elle fournit l'instrument qui permet de surveiller en toute légalité des gouvernants et d'en changer s'ils obtiennent de mauvais résultats, ou s'ils volent, sans devoir attendre une catastrophe et sans verser le sang» ${ }^{1}$. Se trata de garantías jurídico-políticas, que hacen del ser humano, propietario de su parcela de soberanía, un actor de su historia ${ }^{2}$. Éste es libre de escoger a sus representantes. Estos últimos deben "ser su voluntad y su voz" y no sólo portavoces que interpretan sus deseos y sus aspiraciones ${ }^{3}$. Es el pueblo soberano el que detenta el verdadero poder por medio de unas elecciones, de lo cual es responsable una administración neutral e imparcial. Es el poder de las urnas que prima sobre el poder de turno, que no le cabe sino plegarse ante la decisión del pueblo. Este último es libre de renovar su apoyo al gobierno u otorgar su confianza a otro nuevo. En eso consiste la alternancia que es un aspecto fundamental de la democracia. Pues para que el gobierno se mantenga, está compelido a tomar en serio las demandas y las exigencias de la nación para ganar su confianza, sabiendo

1. Revel, J-F., Le regain démocratique, Fayard, Paris, Janvier 1992, p. 281.

2. Tourraine, A., Qu'est-ce que la démocratie? Fayard, Paris, 1994, p. 34.

3. Burdeau, G., La démocratie, Imprimerie Bussière, Saint Armand, 1996, p. 39. 
que su futuro depende de ello. Así destaca el interés de la soberanía popular, sin la cual, la democracia se hace prácticamente imposible 4 .

Sin embargo, la dimensión política dominada por la aritmética, eso es por la sumisión de la minoría a la mayoría, puede convertir el principio de la soberanía popular en un título que legitima la tiranía ${ }^{5}$. Para mostrar que tal riesgo es real, André Philippe dirá: "si mañana, una mayoría pasajera obligaba a los judíos a llevar la estrella amarilla, no tendríamos que inclinarnos delante de esta decisión mayoritaria que sería contraria a los principios más sagrados de nuestra conciencia [...] la voluntad democrática se traduce no sólo por su origen, la expresión de la voluntad de la mayoría del pueblo, sino que también por su contenido, por el hecho de que está conforme a las reglas jurídicas y a las normas morales que caracterizan en un momento dado una civilización y una comunidad nacional"6.

La dimensión política de la democracia, relativa a la gestión de los asuntos públicos, ligados históricamente al principio de libertad, guarda una íntima relación con la dimensión social, basada en el principio de igualdad. De este modo, la filosofía política de la democracia está estrechamente unida a la filosofía moral. Y es esta unidad la que hizo que G. Sartori rechazase la separación de las dos formas de democracias: política y social ${ }^{7}$. El interés

4. Touraine (A.), op. cit., p. 115.

5. Esta interpretación pone en cuestión la tesis de Kelsen basada sobre la voluntad de la mayoría.

6. Discurso pronunciado ante la comisión de la Constitución en 1946, citado por Debbasch, C. et Pontier, J.M., Introduction à la politique, $4^{\mathrm{ème}}$ édition, Dalloz, Paris, 1995, p. 281.

7. Tourraine, A., op. cit., p. 18. de esta unidad consiste en salvaguardar un perfecto equilibrio entre estas dos filosofías de orígenes opuestos.

\subsection{La dimensión social}

La relación de complementariedad, incluso de causalidad que existe entre la dimensión política y la dimensión social de la democracia, la pone de relieve J.F. Revel afirmando que: "en el aspecto económico como, de hecho, en muchos otros aspectos de la gestión de una sociedad, la democracia, en el sentido más humildemente práctica, aporta ante todo el medio para el pueblo de desembarazarse a tiempo y de manera pacífica, sin guerra civil ni insurrección, de un poder que gobierna mal"8.

La dimensión social, de origen ético y moral, interviene para asegurarle al ser humano un umbral mínimo de derecho, a la altura de su dignidad, protegiéndole de los abusos de las autoridades políticas. Por estas razones, numerosos politólogos, interesados en la promoción de los derechos humanos valorizan la primacía del principio de igualdad sobre el principio de libertad. Fascinado por la concepción de Lincoln de la democracia, A.D. Tocqueville dirá: “ la misma mayoría no constituye la fuerza en su totalidad. Por encima de ella, en el mundo de la moral, se encuentran, la humanidad, la justicia y la razón"9.

Una democracia se verifica en la práctica, en la realidad diaria. Es únicamente en estas coordenadas que se puede afirmar que un régimen es democrático o no le

8. Revel, J-F., Le regain démocratique, Fayard, Paris, 1992, pp. 280-281.

9. Véase al respecto, entre otros, La Démocratie, Burdeau, G., Obra citada.. 
es. Por estas razones, G. Burdeau definió la democracia como una «manera de vivir». La esencia de la democracia se encuentra pues en su contenido, en lo que Giovanni Sartori llamó simplemente «la cosa» ${ }^{10}$ de la democracia.

La democracia social que hace de la dignidad humana su principio de base, milita a favor de lo que Lord Bryce llamaba "igual estima para todos" ${ }^{11}$. Una estima que podría desembocar en una igualdad de derechos ${ }^{12}$ y, aún más todavía, en una " nivelación de las diferencias en las condiciones" ${ }^{13}$ sabiendo que la igualdad de las condiciones es un "hecho providencial" que "escapa de la potencia humana"14.

En esta orden de idea, podemos decir que la democracia sociopolítica descansa pura y simplemente en los derechos humanos tal, como son universalmente reconocidos.

Sin embargo, es necesario anotar que la democracia guarda íntimas relaciones con el Hombre. Depende de su evolución, pues éste cambia en el tiempo y/o en el espacio, y de ahí que cubre la democracia de un nuevo vestido y la dota un nuevo sentido. Es decir, es el Hombre quien le da su sentido real y efectivo. De este hecho, defender la universalidad de los derechos humanos, políticos y sociales, que representan por otra parte el núcleo duro de la democracia, no significa de ningu-

10. Sartori, G., Théorie de la démocratie, collection analyse politique, librairie Armand Colin, Malakoff, 1973, p. 3.

11. Citado por Touraine, A., op. cit., p. 122.

12. Ibid.

13. Sartori, G., La théorie de la démocratie, op. cit., p. 372.

14. De Tocqueville, A., citado por Debbasch, C., et Pontier, J.M., op. cit., p. 104. na manera la defensa de una concepción única de la democracia. Numerosos factores tanto históricos como culturales intervienen para dar a la democracia un sentido específico y propio de cada sociedad. "Cada cultura se concibe, pues, como el producto de historia particular"15.

\subsection{La dimensión cultural}

Los valores culturales y morales (tradicionales) son testigo de la fidelidad al pasado y a las raíces. "La cultura democrática no se limita a definir conductas y relaciones humanas dentro de una sociedad modernizada. Sería infiel a su principio central si no afirme la continuidad del pasado con el futuro, la posibilidad de movilizar un patrimonio cultural para crear el futuro [...] La democracia debe salvar de modo absoluto la mayor parte posible del pasado, diríamos incluso de la tradición, para inventar un futuro que sea tanto particular como único, construido alrededor de los principios universales que son la racionalidad y el respeto de la libertad y de la igualdad en derecho de los sujetos humanos"16. Consciente de la imposibilidad de imponer un modelo único de democracia, Alain Touraine deja este margen de diferencia en los pueblos.

Hassan II, ferviente defensor de la excepción marroquí abunda en esta dirección: "Es evidente que la concepción de la democracia no puede ser, y no es lo mismo a Londres, a París, a Estocolmo, a Moscú, a Nueva York, a Tokio y a Rabat. Un sistema universal de gobierno sólo sería imaginable si los hombres y las costumbres

15. Lagroye, J., Sociologie politique, Presse de la Fondation Nationale des Sciences Politiques, Dalloz, Paris, 1991, p. 147.

16. Touraine, A., op. cit. p. 236. 
fueran semejantes en todas partes"17. Sin embargo, "diría que una comunidad de valores - el principio democrático, los derechos humanos, el pluralismo- puede reunir, sin traicionarse a sí misma ni traicionarlos, tradiciones diferentes" 18 .

De estas citas destaca el hecho que la democracia es ante todo una cultura propia de cada país. No puede ni evolucionar ni desarrollarse si las condiciones y los elementos éticos y estructurales de base no son favorables ${ }^{19}$.

De hecho, cada país tiene sus tradiciones, sus costumbres, su historia, su experiencia propia que forjan su identidad. Ésta determina sus huellas y guía sus diferentes preferencias y aspiraciones. Hassan II ironiza con los teóricos de la concepción única de la democracia. «No existen procedimientos industriales que permitan entregar fábricas institucionales llaves en mano. La simple imitación sería estéril»20.

Destaca así una idea muy importante: la democracia debe ser concebida sobre bases realistas. Debe reflejar las especificidades morales, culturales e históricas de cada país.

En Marruecos, el Islam es sin ningún género de duda el cimiento del edificio sociopolítico del país. Conforma su identidad, su historia y su cultura. Asimismo,

17. Hassan II, le défi, Paris, 1976, pp. 79-80.

18. Hassan II, Discurso ante la Asamblea nacional francesa, Paris, el 08/05/1996.

19. Tibi, B., "Démocratie et démocratisation en Islam: la quête d'un Islam éclairé et les contreforce de l'autoritarisme et du fondamentalisme religieux", Revue Internationale de politique Comparée, vol. II, ${ }^{\circ}$ 2, De Boeck Supérieur, Paris, 1995, p. 292.

20. Hassan II, Discurso ante la Asamblea nacional francesa, op. cit. pesó y sigue pesando sobre su concepción del poder. Salvaguardado por la ley suprema ${ }^{21}$ del país y presentado como una constante del régimen ${ }^{22}$, sagrada e intocable por no decir inviolable, la referencia histórico-religiosa de la democracia hace aún más complejas las relaciones entre el Estado, como forma autoritaria, y el ciudadano, en principio, titular de la soberanía nacional. Esta complejidad, que da cuenta de la particularidad del sistema político marroquí, es la clave para abordar de manera comprensiva este régimen.

El Islam ocupó siempre buena parte del discurso de su Majestad el Rey Hassan II. Siempre ha sabido, cuando la ocasión lo permitía, usar los conceptos religiosos para transmitir mensajes, defender principios o actitudes, asegurar el matrimonio entre lo temporal y lo espiritual, y por consiguiente salvaguardar la continuidad de su posición en la cabeza del poder. Sin embargo, conciliar dos tipos de legitimidades: una tradicional y la otra moderna, no es una tarea fácil en un período en el cual la modernidad suscita una especie de fascinación engañosa según el Soberano:

"Me parece que el uso del término 'modernidad' en la vida política puede dar lugar a malos entendidos. Algunos de los que lo emplean parecen creer que la modernidad

21. El artículo 100 de la Constitución dispone que "la forma monárquica del Estado, así como las disposiciones relativas a la religión musulmana no pueden ser objeto de una revisión de la Constitución".

22. Las constantes del sistema político marroquí son: 1. La forma monárquica, 2. La religión islámica, 3. La integridad territorial. Para más detalle, véase, Darif, M., Les droits de l'homme au Maroc, Publication de la revue marocaine de la sociologie politique, imprimerie les nouvelles connaissances, Rabat, 1994, p. 214. 
política exige, a pesar de la geografía y de la historia, la uniformidad de las instituciones en todos los Estados del mundo. Se equivocan, ya lo he dicho. Otros, creyéndose más realistas, piensan, por el contrario, que la modernidad está fuera de alcance en los países en los que el respeto de la tradición se opondría a cualquier cambio real. No se equivocan menos» ${ }^{23}$.

Tradición -modernidad, Rey-comandante de los creyentes, democracia-Islam, etc... son conceptos brillantemente utilizados por el Rey. El ejemplo de la alternancia es por excelencia la prueba de ello.

\section{Aspectos y retos de la alternancia en Marruecos}

El déficit socioeconómico de las últimas tres décadas ${ }^{24}$ y la aceleración de los cambios mundiales de los años ochenta (caída del Muro de Berlín, Guerra del Golfo, descomposición de la Unión soviética, caída de los regímenes totalitarios, ascenso sin precedentes del integrismo.), van a influir considerablemente sobre las opciones políticas y constitucionales de Marruecos $^{25}$. El soberano señala esta coyuntura en varios discursos del trono:

"El fin del año pasado ha experimentado cambios políticos e ideológicos que nadie veía. En la Unión Soviética y en la Europa

23. Hassan II, Alocución ante la Asamblea Nacional Francesa.

24. Para más detalle, véase nuestra tesis, La Notion de Démocratie au Maroc, Essai d'Analyse des Discours du Trône (1962-1995), thèse pour le doctorat en sciences politiques, Université des Sciences politiques, Université des Sciences Sociales Toulouse I, 1998.

25. Louzi, A., "La question constitutionnelle et le processus démocratique au Maroc", REMALD, Rabat, $n^{\circ}$ 5, 1996, p. 153.
Oriental, una revisión filosófica y radical de los métodos y sistemas se ha realizado. Estas transformaciones permiten acercar las doctrinas políticas, a confirmar la distensión política entre los bloques, y acariciar la esperanza de que algún día las naciones se unan alrededor de la glorificación de la libertad, la consolidación de las bases de la democracia y el establecimiento de los fundamentos de la justicia"26.

"El año pasado ha sido fértil en acontecimientos múltiples y diversos. El mundo sigue una senda de transformación esbozada antes de finales de los años 80. Es profunda, real y, con toda probabilidad, irreversible"27.

Por su parte, la oposición aprovechará esta coyuntura, en plano nacional e internacional, para sostener las demandas de democratización. En estas coordenadas, el 17 de mayo anuncia la necesidad de una serie de reformas entre las cuales destacan ${ }^{28}$ la constitución de un Gobierno representativo y homogéneo, la sepa-

26. El Rey Hassan II, Discursos y entrevistas, editado por el Ministerio de la Información, tomo X, 3 marzo 1990, Rabat, p. 458.

27. El Rey Hassan II, Discursos y entrevistas, editado por el Ministerio de la Información, marzo 1993-1994, Rabat, p. 8.

28. En el plano político-constitucional, la Koutla anuncia: " [...] también, los partidos nacionales democráticos proclaman su compromiso de llevar una acción común, animada por la misma voluntad para concretar los objetivos siguientes:

[...] Instauración de una reforma constitucional profunda que establecería los fundamentos de un Estado de derecho, reforzase el poder de la ley, y asegurase la democratización y la modernización de las instancias del Estado a todos los niveles. Esta reforma deberá instituir una separación efectiva de los poderes delimitando las responsabilidades de cada órgano; deberá estipular la constitución de un gobierno que sea representativo de la mayoría popular, y que asuma todas sus responsabilidades ante la cámara de los representantes. 
ración real de poderes, la celebración de elecciones libres y supervisadas y la supresión del sufragio indirecto ${ }^{29}$.

Ante el fracaso de los partidos en el poder, rechazados por el ciudadano que sigue reclamando cambios y reformas ${ }^{30}$, en el año 1992 el soberano opta por una

Esta reforma deberá al mismo tiempo asegurar la independencia de la justicia y proteger los derechos y las libertades de los ciudadanos. Deberá elaborar un marco institucional que sea eficaz, capaz de satisfacer las reivindicaciones y las ambiciones legítimas del pueblo para el desarrollo, el progreso y el bienestar, obrando por la igualdad de oportunidades, la solidaridad y la justicia social, con vistas a edificar una sociedad moderna que sea fundada en el Islam y se refiera a todos los valores culturales y de civilización del pueblo marroquí.

Establecer instituciones democráticas tanto a nivel local, regional y profesional como nacional, que emane del pueblo y goce de su confianza. Esto exige que todas las elecciones generales, locales, profesionales y legislativas y todas consultas populares sean rodeadas de las garantías políticas y jurídicas,... de crear entre ellos un clima de confianza en el proceso electoral, y de asegurarles de su carácter libre y honrado. Estas son las únicas garantías susceptibles de fundar la credibilidad de las instituciones representativas.

Para más detalles véase el periódico l'opinión del 27 de mayo de 1992.

29. El Soberano opuesto a esta reivindicación, en nombre de la democracia, dirá:

"Si no asociamos plena y directamente a los elegidos municipales, verdaderos representantes de la descentralización, a otros elegidos, con vistas al ejercicio de las responsabilidades locales y regionales, entonces habremos causado perjuicio a la descentralización". Hassan II, Discursos y Entrevistas, Editado por el ministerio de la información, Rabat, marzo 1992 y marzo de 1993..

30. Jamai, K., "Le champ politique marocain, les véritables enjeux", l'opinion du 16 de noviembre 1993, citado en A.A.N., Paris, Editions du CNRS, 1993, p. 545. revisión constitucional. Así, el Rey plantea nuevas reglas del juego para sosegar el clima social cada vez más agitado. La nueva Constitución se hace eco de la alternancia, considerada como un tema recurrente en los discursos regios de los años noventa.

Dada la divergencia, entre la visión real y la de la Koutla, respecto de la alternancia, ésta va a ser objeto de serios debates durante unos cuatro años, durante los cuales la concepción real acabará triunfando. Dos grandes etapas se pueden distinguir en este período: la primera se caracteriza por un fracaso de las conversaciones (2.1) y la segunda, da origen, por primera vez, a la alternancia, tal como fue concebido por el difunto Rey Hassan II, en tanto que opción irreversible para consolidar la democratización de las instituciones (2.2).

\subsection{El fracaso de las conversaciones}

Desde el principio hemos sostenido que la alternancia consiste en la transferencia del poder de la mayoría a la oposición de conformidad con una serie de normas bien establecidas. Este principio pone de relieve dos normas fundamentales que representan las condiciones necesarias para el éxito de la alternancia. La primera regla es jurídica, y está vinculada al aspecto constitucional de las normas, que definen la alternancia y garantizan el éxito y el respeto de la práctica política en nombre de la soberanía de la Constitución en tanto que norma suprema. La segunda es política, y se refiere a la necesidad de unas elecciones libres y transparentes ${ }^{31}$ que expresen las nuevas tendencias so-

31. EL Mossadeq, R., Les dédales de l'alternance, En-Najah 1996, pp. 11 et 107. (En árabe). 
ciales, políticas y electorales de la sociedad. Dicho de otro modo, el resultado de las elecciones resulta ser un verdadero barómetro susceptible de dar cuenta de las nuevas tendencias de la sociedad ${ }^{32}$. Únicamente la transparencia electoral puede otorgar a la alternancia todo su sentido y su vivacidad. Por ello, el discurso regio hace de las elecciones a la vez una garantía de apertura y un paso hacia un cambio real ${ }^{33}$. Con ocasión del discurso del trono, el Soberano dirá:

"[...] queremos que nuestras elecciones internas se hagan con la máxima transparencia... De hecho, queremos borrar las zonas de sombras y tener de nuestro pueblo, una fotocopia lo más acorde posible con su realidad. Sólo unas elecciones libres, leales y creíbles pueden ofrecernos esta fotografía. Sabemos que es el deseo de todos... ". "Quiero que los resultados de esta votación me traduzcan la exacta fisionomía del país. Me interesa conocer el sentimiento de las masas con las que vamos a emprender el asalto del siglo XXI, las ambiciones de los nuevos elegidos, sus éticas, sus puntos de vista sobre las cuestiones económicas y sociales" 34 .

Estas declaraciones explícitas confirman la firme voluntad del Rey de convertir estas elecciones en una ruptura con el pasado y un avance hacia el futuro.

No faltan señales de un verdadero cambio político. Dos acontecimientos adquie-

32. Vamos a limitarnos únicamente al estudio del aspecto político de la alternancia relativa a las elecciones de 1993. Nuestra elección es justificada por la importancia de éstas y sus consecuencias sobre la vida política marroquí y sobre el devenir de la alternancia.

33. Sautucci, J.C., "Maroc chronique intérieur", A.A.N., Paris, Editions du CNRS, 1992, p. 838.

34. El Rey Hassan II, Le monde, Paris, el 2 de septiembre 1992. ren un especial significado: por un lado, la puesta en libertad de Noubir Amaoui, indultado por el Rey el 12 de julio de $1993^{35}$, y la posibilidad de elegir al Primer Ministro entre los miembros de la Koutla por otro. A este respecto, el Soberano afirma ante Anne Sinclaire que: "el hecho de ver como un avance extraordinario el hecho de que yo tomase como Primer Ministro a un hombre que estaba en la oposición no sería... más que la lógica, si queremos seguir implacablemente la lógica de la Constitución"36.

Sin embargo, el aspecto más convincente de esta iniciativa real de apertura radica, sin duda, en los resultados de la primera vuelta de las elecciones legislativas. En efecto, la retirada del Ministerio del Interior del juego electoral, resulta fructífera, a pesar de algunas irregularidades ${ }^{37}$ que han afectado estas elecciones. La Koutla obtiene 99 escaños, Le Wifaq ${ }^{38}$ (U.C, M.P.P.D.D., M.N) 88 escaños y el R.N.I, que se define como un partido social demócrata ${ }^{39}$ y que ha manifestado su in-

35. Noubir Amaoui es el secretario general de la confederación democrática del trabajo (C.D.T). Condenado a dos años de prisión por haber proferido declaraciones injuriosas en contra del gobierno marroquí, acusándolo de corrupción.

36. El Rey Hassan II, «emisión 7 sur 7» en la cadena de televisión francesa «TFI», in Discursos y entrevistas, marzo 1993 - marzo 1994, editado por el Ministerio de la Información, Paris, 1994, p. 66.

37. El poder del dinero reemplazó él de las urnas. En efecto el precio y el valor de los votos varían según las ciudades: entre 50 y 200 tipos de $\mathrm{DH}$ a Rabat, hasta 2000 DH en Agadir, 10.000 tipos de DH por la retirada de un candidato molesto. $C f r$. Sautucci, J.C, Marruecos. Crónica Interior, op. cit., p. 848.

38. Le Wifaq nace justo antes de la segunda vuelta para formar una coalición capaz de hacer frente a la Koutla.

39. Sautucci, J.C, op. cit. p. 512. 
tención de unirse a la Koutla para garantizarle una mayoría tranquila, obtiene 28 escaños.

La honestidad relativa de estas elecciones, cuyos resultados recuerdan extrañamente a las elecciones legislativas de 1963, sorprendió a todos los apasionados de la vida política marroquí. Bernabé López García comentando esta situación declara que "hasta después del 25 de Junio nunca el mapa político de Marruecos se había parecido a sí mismo"40.

Nada en la vida política marroquí permite sospechar que la alternancia es de cara al futuro una elección irreversible. El menor gesto se interpreta favorablemente hasta tal punto que A. Youssefi confía, en vísperas del sufragio indirecto, en Fathallah Oulalou, miembro de la oficina política, "la tarea de inventariar los cuadros próximos al partido y que puedan contribuir al ejercicio de responsabilidades gubernamentales" ${ }^{41}$.

Los resultados de la segunda vuelta son muy decepcionantes. Ponen fin a las ilusiones de la Koutla que estaba "construyendo castillos en España".

Ironía electoral, la agrupación "Entente" gana 66 escaños de un total de 111 para cubrir. La "Koutla" se conforma con 23 asientos. Estos resultados causan cuanto menos cierta perplejidad del observador, ya que el Wifaq que acaba de obtener el $72,40 \%$ de los votos, eso es 50 escaños, en las elecciones al Colegio

40. Lopez Garcia, B., "Le Makhzen, la amma et l'arbitre au Maroc: Administration et société civile aux élections locales et législatives 1992-1993", A.A.N, Paris, Editions du CNRS, 1992, p. 420.

41. Barrada (H.), "Maroc, pourquoi l'opposition refuse le pouvoir", Jeune Afrique, n 1714, del 11 al 17 de noviembre 1993, Paris, p. 16. de Consejos Municipales ${ }^{42}$ sólo obtuvo el $43.25 \%$ de los escaños en las elecciones municipales ${ }^{43}$. El «Wifaq», al que se han sumado numerosos tránsfugas (de derecha y también independientes), obtiene 169 escaños y supera la mayoría absoluta (167 asientos) $)^{44}$.

Para la oposición con 123 escaños, la decepción es grande, tanto más cuanto que el "R.N.I", que podría ayudarle a alcanzar la mayoría, era el favorito de esta segunda vuelta ${ }^{45}$ sólo consiguió 13 escaños. Sorprendidos, los responsables de este partido denuncian el fraude: «una cuestión de lógica aritmética: ¿Cómo explicar que el R.N.I. que posee dos veces más representantes locales que el U.C, tiene 8 diputados designados por el Colegio de

42. El artículo 43 de la constitución dispone: “[...] la Cámara de los representantes comprende, en la proporción de los dos tercios, a los miembros elegidos por sufragio universal directo y en la proporción de un tercio a los miembros elegidos por un cuerpo electoral compuesto por los consejeros municipales, así como por los miembros elegidos por colegios electorales que comprenden a los elegidos de las cámaras profesionales y los representantes de los asalariados".

43. El Mossadeq, R., "Jeu de consensus et développement constitutionnel et électoral au Maroc", A.A.N., 1992, Paris, Editions du CNRS, p. 463.

44. Barrada, H., "Pourquoi l'opposition refuse le pouvoir", Jeune Afrique, $\mathrm{n}^{\circ} 1714$, Paris, 1993, p. 17.

45. Es preciso anotar que el R.N.I. consiguió en las elecciones municipales 4829 votos, o sea el $21.71 \%$ de escaños. Este resultado le permitió dejar atrás a todos los partidos de la Administración, entre los que estuvieron el U.C, que sólo pudo obtener 2992 votos, eso es el $13.46 \%$. Para más detalles véase Basri, $\mathrm{D}$, La descentralización de Marruecos del municipio a la región, Colección Edificación de un Estado moderno, Nathan, 1994, pp. 90-93. 
Consejeros Municipales mientras que el U.C obtiene 20 ? ${ }^{46}$.

El análisis de los resultados de esta segunda vuelta, que dejaron estupefactos ${ }^{47}$ a los partidos de la oposición ${ }^{48}$, demuestra que el Majzen ha desempeñado bien su papel de manera que ninguna formación política se sintiera indispensable"49. Este saber hacer, sumado a la libertad de actuación del Ministerio del Interior, revela el peso y la amplitud del poder del que goza este gobierno paralelo que ha infringido las consignas y garantías reclamadas por el Rey ${ }^{50}$ :

"Así, las próximas elecciones deben ser objeto de atención especial por parte de todos. Por nuestra parte, nos esforzaremos para que sus resultados sean un reflejo exacto de las aspiraciones profundas de Nuestro pueblo. Velaremos a que las próximas elecciones sean libres y transparentes, tal como lo exige cualquier democracia real y auténtica. Al garantizar a las próximas elecciones todas las condiciones de libertad y sinceridad, habremos cumplido con nuestro deber".

46. Gateau, R., "le choix du Roi", Jeune Afrique, $\mathrm{n}^{\circ}$ 1708, Paris, 1993, p. 18.

47. IBID.

48. Al contrario, el P.P.S, estaba satisfecho de los resultados que obtuvo (12 escaños). Resultado que le permitió por primera vez formar un grupo parlamentario (véase a este respecto, Barrada. H., Por qué la oposición niega el poder). El P.P.S. en la persona de A. Yata pareció poco reticente, por no decir favorable, a las propuestas regias. Y ello, en contra de los tres otros miembros de la Koutla (O.A.D.P, U.S.F.P, P.I). La actitud del P.P.S y otros partidos de Koutla, Véase declaración de El Yazaghi, "Entre solicitantes y rivales", El liberal, $\mathrm{n}^{\circ}$ el 82, 15 de diciembre de 1994, p. 13.

49. Gateau, R., "le choix du Roi", Jeune Afrique, n ${ }^{\circ}$ 1708, Paris, 1993, p. 18.

50. El Rey Hassan II, Discursos y entrevistas, marzo 1991-marzo 1992, Editado por el Ministerio de la Información, Rabat, 1992, p. 23.
Sin embargo, el soberano tiene algo de que alegrarse. Este resultado lo satisface plenamente, ya que le permite realizar su deseo: crear la bipolaridad política tan esperada. A este respecto el soberano dirá:

"El destino, querido pueblo, ha querido en los últimos meses, que me encuentre con una alegría real y también con asombro -en presencia de dos coaliciones: El «Bloque Democrático» y «la Entente Nacional». Entonces me dije: "No debemos dejar que esta oportunidad escape a mi pueblo [...]. Porque creo que la democracia eficaz y fructífera funciona como una báscula, que nunca tiene más de dos bandejas, una de las cuales puede inclinarse por razón de la desigualdad de pesos. La existencia de estas dos bandejas ha permitido a países como Inglaterra y los Estados Unidos de América introducir la alternancia, realizar el cambio y la renovación... A partir de esta constatación y sin entrar en consideraciones aritméticas para distinguir a la mayoría de la minoría $\mathrm{y}$, teniendo en cuenta, querido pueblo, mi deseo de renovación y cambio, me he dicho: " ha llegado el momento de la puesta en marcha de la alternancia"51.

En efecto, la alternancia sigue al orden del día, pero debe adaptarse "al particularismo marroquí". La alternancia no saldrá de las urnas. Será impuesta desde arriba ${ }^{52}$. ¡una alternancia en marroquí!

El desarrollo de las elecciones legislativas de 1993 expresa perfectamente el espíritu y la noción del poder en Marruecos: cambiar sin perder el poder de control, ámbito (el control) reservado estrictamente a la institución monárquica. Esto expre-

51. El Rey Hassan II, Discursos y entrevistas, marzo 1993 - marzo 1994, Editado por el Ministerio de la Información, Rabat, 1992, p. 212.

52. Barrada (H.), op. cit., p. 16. 
sa claramente el dilema de la democracia en Marruecos, que oscila entre la voluntad de cambio y el poder de materializar este cambio. Preocupado por la amplitud de sus prerrogativas, el soberano no puede renunciar a su poder o compartirlo.

En estas condiciones, ¿qué concepto podría tener la alternancia, sabiendo que ésta es en los países democráticos sinónimo de la libre acción del Gobierno (partido mayoritario) en la definición de la política del Estado? En otras palabras, ¿cómo se puede proceder a la alternancia, cuando es el Rey quien posee todos los poderes?

El discurso inaugural de la primera sesión parlamentaria 1993 es explícito. En esa ocasión, el soberano dirá:

"Entonces, convocaré a los representantes de la Koutla y luego a los del Wifaq. A unos y a otros, les preguntaré si quieren participar en el Gobierno. Si una de las dos partes desea participar, tendrá que presentarnos su programa. Luego nombraremos al Primer Ministro que se presentará ante sus señorías para pedirles su confianza"53.

Este extracto, por muy claro que sea, está Ileno de connotaciones. Incluye todas las destrezas que se esconden detrás del desafío de la política de alternancia. En efecto, el nombramiento del Primer Ministro por el Rey es el principal desafío. Expresa la competencia entre el Rey y el Movimiento Nacional para el Control del Poder Ejecutivo. La versión final del artículo 24, que confirma la firme voluntad del Soberano de reservarse el control del poder ejecutivo, es un buen testimonio de las reticencias del

53. El Rey Hassan II, "Ouverture de la première session de la nouvelle législature 1993-1994", Discursos y entrevistas, marzo 1993 - marzo 1994, Editado por el Ministerio de la Información, Rabat, 1992, p. 196.
Rey ${ }^{54}$ a lo largo de la redacción del proyecto de Constitución de 1992, proyecto que pretendía limitar las prerrogativas reales. He aquí dos pruebas ello:

En respuesta a E. Laurent el Rey afirma que "El Primer Ministro es a partir de ahora elegido por mí mismo, en función de la mayoría parlamentaria que se desprende de las urnas, y el programa de su Gobierno se somete a la aprobación del Parlamento. Así pues, estamos terminando y consolidando lo que ustedes denominarían como un sistema de monarquía constitucional y parlamentaria" 55 .

El proyecto del artículo 24 fue redactado en los siguientes términos: "El Rey nombrará al Primer Ministro. A propuesta del Primer Ministro, nombrará a los demás miembros del Gobierno y pondrá fin a sus funciones. Pondrá fin a las funciones del Gobierno, ya sea por iniciativa propia o por dimisión del Gobierno"56. Ahora bien, la versión final del artículo 24, "a propuesta del Primer Ministro, nombra a los demás miembros del Gobierno. Puede poner fin a sus funciones", confirma la superioridad del Rey sobre los partidos políticos. El Rey, presunto árbitro independiente entre los poderes mencionados en el artículo $24^{57}$, toma posición y se convierte no sólo

54. EL Mossadeq, R., "Jeu de consensus et développements constitutionnel et électoral au Maroc", A.A.N., Editions du CNRS, 1992, Paris, p. 441.

55. Hassan II, La mémoire du Roi, Entrevista con Eric Laurent, Plon, Paris, 1993, p. 98.

56. Al-Anba du 21 agosto 1992.

57. En el momento del aniversario de Marca Verte, el Soberano hizo un balance sobre las negociaciones. Dirá:

"Por añadidura, (los partidos de Koutla) han olvidado una cosa, a saber que el nombramiento del Gobierno depende constitucionalmente de mis atribuciones. 
en una parte importante en el conflicto, sino en la primera fuerza interesada en la alternancia. Así, nos damos cuenta de que el conflicto no afecta en absoluto a los partidos políticos, que en las democracias modernas pretenden acceder al poder. Es un pulso entre el Rey y el movimiento nacional. El Wifaq, ya metido en la lógica administración, no resulta concernido.

Para salvaguardar su monopolio, el soberano se reserva otros tres ministerios: el Ministerio del Interior, Asuntos Exteriores y de Justicia. El Rey justifica su decisión del siguiente modo:

"El Primer Ministro debe conocer perfectamente sus expedientes. Ahora bien, una minoría de ustedes abandonó el Gobierno hace ocho años y los demás lo hicieron hace treinta y tres años. ¿Cómo, en estas condiciones, puedo elegir a un Primer Ministro entre ustedes? Estaría llamado a dirigir un gobierno sin saber nada de los asuntos que tendría que tratar y que él mismo ignora. He añadido: Por ahora, crean una coalición. Ahora bien, si elijo al Primer Ministro faltaría la solidaridad y la homogeneidad que he deseado. Aunque ahora estén agrupados en una coalición, cada partido conserva su especificidad y la confianza no reinaría forzosamente entre ustedes. Cada noche, pasas el tiempo espiando los hechos y los gestos del Primer Ministro en un intento de informarse sobre lo que quizás esté tramando con su partido y que podría reservarles algunas sorpresas para el día siguiente. «Por otro lado, la Constitución me confiere

El Primer ministro, lo nombro personalmente. Propone los ministros. No los nombra. No los designa. Los propone, he aquí todo. De tal suerte que si me obstinara, podrían transcurrir dos meses durante los cuales me presentaría cada día una lista de cincuenta personas y le diría cada vez: "no los quiero". Porque ningún artículo de la Constitución me obliga a aceptar lo que el Primer ministro designado propone". el derecho a designar personalmente al Primer Ministro. Éste es uno de mis derechos constitucionales».

Por otro lado, he subrayado esto: el Ministerio de Asuntos Exteriores responde ahora a exigencias de orden interno, nuestra vida económica, agrícola y comercial está estrechamente ligada a nuestra política exterior, tanto con respecto a la Comunidad Económica Europea como a nivel regional e internacional.

Luego les dije: «En la Guerra del Golf, les he recibido como "koutla». Entonces su postura era extremista. Todo el mundo, incluida Rusia, estaba de un lado y ustedes solos estaban por el otro. Les dije «si ustedes, los partidos de la «koutla», se aferran a esta rígida posición, cierran ante ustedes las puertas del departamento de Asuntos Exteriores, porque si confío esa cartera a uno de ustedes, Marruecos se quedaría aislado.

Por otra parte, la justicia es la base del poder y la justicia se ha administrado tradicionalmente en «nombre de Su Majestad el Rey». Una formación o un movimiento político, cualquiera que sea, no puede ocupar tal puesto. Si la voluntad divina sigue siendo aceptada por el hombre, no cabe decir lo mismo con relación a la injusticia de los hombres para con sus semejantes.

En cuanto al Interior, nunca confiaré a un partido, cualquiera que sea, este departamento» ${ }^{58}$.

La mano del Soberano sobre estos cuatro "ministerios de soberanía" expresa la voluntad de la institución monárquica de reservarse los medios necesarios para desempeñar bien su función de árbitro. Esto revela el desafío oculto detrás el abandono de una alternancia impuesta por las urnas. Ésta requiere que el Gobierno sea elegido entre la formación mayoritaria en el Parlamento y, al mismo tiempo, que el

58. El Rey Hassan II, Discursos y entrevistas, marzo 1993 - marzo, Rabat, 1994, pp. 217-218. 
Rey tenga que designar al Primer Ministro en el seno de esta formación política ${ }^{59}$. Principio que limita enormemente la prerrogativa real sobre la elección del Primer Ministro ${ }^{60}$. Este comportamiento pone de relieve la supremacía y la libertad reales en la interpretación de la Constitución.

Sin embargo, si la Constitución no dispone que el Primer Ministro deba ser elegido entre la mayoría parlamentaria como señala su Majestad ${ }^{61}$, la tradición democrática quiere que el líder del partido o de la coalición con la mayoría parlamentaria sea Primer Ministro y que el Gobierno esté formado por miembros de la misma ${ }^{62}$. En caso de no ser así, la alternancia va a tomar un sentido ajeno las tradiciones democráticas. Tendría una connotación propia del particularismo marroquí. El soberano propone a la Koutla, coalición minoritaria en el Parlamento, formar al Gobierno. A este respecto, el Rey dirá:

"A pesar del resultado que ustedes han conseguido en las elecciones, y a pesar de que el número de sus representantes electos en el Parlamento no represente la mayoría, se merecen cuantitativa y cualitativamente ser invitado a trabajar a nuestro lado para que cada uno de los partidos concernidos pueda aportar, individual o colectivamente, una nueva metodología, un nuevo estilo del que yo mismo disfrutaré, y para que los nuevos

59. El Mossadeq. R., "Les dédales de l'alternance", op. cit., pp. 50-51 (en árabe).

60. El Mossadeq (R.), "Jeu de consensus et développement constitutionnel et électoral au Maroc", A.A.N., Paris, Editions du CNRS, 1992, pp. 441-442.

61. EL Mossadeq, R., "Les dédales de l'alternance", op. cit., p. 58.

62. Véase, la intervención de Mohammed Ben Said, secretario general de la O.A.D.P, respecto del programa de gobierno, in "ANOUAL", Casablanca, 28-29/11/1993. ministros puedan, por su parte, disfrutar de mi larga experiencia en la materia"63.

La visión regia tiende a transformar la alternancia contractual y democrática en una alternancia concedida. De esta propuesta se hará eco en el informe del P.P.S.A. Yata, Secretario General del Partido, en un informe presentado al Comité central el 03 de octubre de 1993: "La Koutla no tiene la mayoría parlamentaria, pero goza de una mayoría popular, así como del apoyo y solidaridad de las poblaciones. Es cierto que todas las categorías del pueblo están con estas fuerzas nacionales y progresistas y creen firmemente en las capacidades de sus hombres. En nuestra opinión, esto debe tenerse en cuenta, porque es un dato basado en una constatación justa y sólida. Si queremos garantizar la paz y la estabilidad de nuestro país, la Koutla debe asumir la responsabilidad de formar al Gobierno"64.

Estas posiciones afectan tanto a la democracia como a la integridad de este partido de izquierdas que aboga por la reforma y la renovación de las instituciones. No se puede concebir una mayoría popular o política sin la existencia de una mayoría aritmética en el Parlamento. Una es necesariamente la razón de ser de la otra.

La declaración del soberano, con ocasión de la marcha verde, pone de relieve la incontestable supremacía de la institución monárquica sobre el Gobierno. Su existencia depende enteramente de la voluntad regia ${ }^{65}$. En esta ocasión, el Rey dirá:

63. El Rey Hassan II, "discurso a la ocasión de la marcha verde", Discursos y entrevistas, marzo 1993 - marzo 1994, Editado por el Ministerio de la Información, Rabat, 1994, pp. 212-213.

64. Citado por EL Mossadeq, R., "Les dédales de l'alternance", op. cit., p. 92. (traducido del árabe). 65. EL Mossadeq, R., op. cit., p. 82. 
"[...] He hecho a los partidos del bloque democrático la promesa de una estabilidad política de tres años como mínimo pero que podría llegar hasta seis años, hasta el año 2000. Me gustaría tener un acuerdo con ustedes, un Pacto en virtud del cual no se votaría en contra si el Gobierno plantea la cuestión de la confianza"66.

En estas condiciones, la mayoría, que no podía ir contra la voluntad real, no entendía en absoluto que fuera descartada ya que tenía la mayoría numérica necesaria para constituir "el gobierno"67. En cuanto a la Koutla, consciente de los riesgos que puede correr, aun aceptando la oferta real, se niega a formar Gobierno, ya que una alternancia otorgada e impuesta desde arriba limitaría su independencia y la implicaría en el desafío del poder.

El 14 de octubre de 1994 surge un nuevo intento. El soberano invita a la oposición a formar Gobierno, incluido el Primer Ministro. La Koutla, de acuerdo en principio, plantea una serie de condiciones para garantizar el éxito de esta obra a saber, la elección directa de todos los diputados, la limitación de la hegemonía del Ministerio del Interior cuyas prerrogativas no dejan de crecer, la constitución de un organismo constitucional encargado de las elecciones $^{68}$ y la constitución "de un gobierno responsable, homogéneo y solidario en el

66. El Rey Hassan II, "Discurso a la ocasión de la marcha verde", Discursos y entrevistas, marzo 1993 - marzo, Rabat, 1994, Editado por el Ministerio de la Información, 1994, p. 213.

67. Znagui, B., "Droite jolie droite, es-tu encore présentable ? Libération, Casablanca,13 Enero 1995.

68. Boucetta, M., "Meeting populaire des partis démocratiques à l'occasion du $51^{\text {ème }}$ anniversaire du Manifeste de l'indépendance et de la démocratie», l'Opinion, Casablanca, el 14 de enero 1995, p. 3. que el Primer Ministro asuma la plena responsabilidad en el seguimiento y la evaluación de la acción de los Ministros"69.

Según M. Elyazghi, estas condiciones, entre otras ${ }^{70}$, constituyen el espíritu de toda reforma política, económica, social, cultural y administrativa ${ }^{71}$. Esta actitud marca el comienzo de un proceso consensuado entre el Palacio y la Koutla. Ésta, que acepta la constitución de un gobierno "al margen de los datos parlamentarios"72, considera que esta alternancia consensuada no es más que una transición hacia la alternancia democrática.

El Elyazghi afirma que: "consideramos que es una alternancia consensuada para alcanzar una alternancia real que sólo puede ser el resultado de un voto popular"73. La Koutla precisa que "el Gobierno capaz de poner a Marruecos en la vía del cambio debe ser, según la Constitución, un gobierno responsable, fuerte, coherente y solidario para ejercer plenamente sus poderes. Responsable porque es controlado por el Rey y por el Parlamento, fuerte por la confianza del Rey y del apoyo parlamentario y popular, coherente por una visión nueva de su estructura, de su formación, de sus directivas generales y sectoriales, solidaria en sus posiciones y sus políticas interiores y exteriores. Así será un gobierno capaz de

69. Mémorandum dirigido a su Majestad el Rey el 25 de abril 1996 por los partidos de la Koutla, p. 6.

70. Véase, Le Memorándum presentado a S.M. el Rey, el 1 de noviembre 1993.

71. El Yazghi, M., "Entre postulants et rivaux", Le libéral, n 82, 15 de diciembre 1994, p. 13.

72. Naim, K., "Une grossesse extra-utérine", L'Opinion, Casablanca, 14 de enero 1995, p. 1.

73. El Yazghi, M., "Entre postulants et rivaux", op. cit. p. 12. 
aplicar un programa que combine las exigencias del desarrollo económico y social y del equilibrio fiscal".

La llamada de la Koutla a formar un gobierno homogéneo es una forma de excluir a Basri, Ministro del Interior, que disfrutaba de un estatuto especialmente superior al de todos los miembros del Gobierno. Bensaid señala a este respecto que: "su situación (Ministerio del Interior) se ha vuelto anómala ya que posee la autoridad territorial, la seguridad, los consejos municipales, el urbanismo, el medio ambiente y la información. Esto no puede seguir así porque de este modo el Ministerio constituiría en sí mismo un gobierno paralelo"74.

Así, el conflicto entre el Rey y la Koutla se circunscribe al Ministerio del Interior, verdadero gobierno paralelo ${ }^{75}$ : "Nosotros, en tanto que tres partidos democráticos, estamos dispuestos a asumir nuestras responsabilidades en el marco de un gobierno transitorio que lleve a cabo reformas constitucionales y designe una instancia que patrocine las elecciones, un gobierno independiente y fuerte en el que no hay lugar a "super-ministro", para realizar una verdadera alternancia que emane de instituciones creíbles"76.

74. Ben Said, M., “Anoual”, Casablanca, el 12 de enero 1995. (Traducido del árabe).

75. El Yazghi, M., Entrevista en el periódico «ALQODS», publicado en "Al Ittihad Al Ichtiraki», Rabat, el 9 enero 1995, p. 3. (Traducido del árabe).

76. IBID. En su memorándum del 25 de abril de 1996, los partidos de Koutla hacen ver que:

"una de las causas de disfunción [del gobierno] reside en la dimensión importante que tomaron las múltiples prerrogativas del ministerio de la Información, dimensión que le alejó de sus ámbitos de competencias tradicionales. Por esta razón es importante restablecer el equilibrio entre los diferentes departamentos ministeriales".
Al negarse a aceptar los requisitos de la Koutla, el Rey no hace más que aplicar su decisión adoptada el 6 de noviembre de 1993: "En cuanto al interior, nunca confiaré a un partido cualquiera, este departamento", y anuncia el aplazamiento de la alternancia.

El interés del soberano por este departamento demuestra hasta qué punto el Rey quiere reservarse los medios necesarios para el control del Estado ${ }^{77}$ y consolidar su condición de garante o incluso de tutor de las instituciones políticas y constitucionales ${ }^{78}$.

Tras el aplazamiento de la alternancia, el Sr. Boucetta dirá: "Un comunicado del Gabinete Real difundido hoy nos enseña que Su Majestad el Rey ha aplazado la constitución de un gobierno de

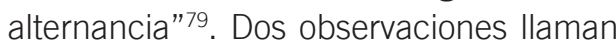
nuestra atención:

- Es el Rey quien decide libremente el destino de la alternancia.

- Los partidos de la Koutla han reaccionado de modo favorable a la decisión del Rey.

Ambas ideas confirman dos hipótesis:

- Los partidos de la Koutla no tienen, como pretenden o cuanto menos como creen, una mayoría política que les apoye. Porque si así fuera, estos partidos habrían de una manera o de otra impugnado la decisión real.

77. Véase, Al Alam, Rabat, el 7 de noviembre 1993, p. 2.

78. EL Mossadeq, R., "Les dédales de l'alternance", op. cit. p. 84.

79. Boucetta, M., "Meeting populaire des partis démocratiques à l'occasion du $51^{\text {ème }}$ anniversaire du manifeste de l'indépendance et de la démocratie», l'Opinion, Casablanca, el 14 de enero 1995, p. 3. 
- Esta hipótesis confirma la razón por la que la idea de la alternancia ha sido abortada. Dicho en otros términos, el número de abstenciones (37.25\%) y del voto en blanco $(13.01 \%)^{80}$, eso es el $50.26 \%$ de los votantes, expresa la desaprobación de las diferentes alternativas propuestas y anima una búsqueda inesperada de otra opción, por no decir otra ideología.

Cualquiera que sea la importancia de la alternancia en la democratización del país, y la limitación de la acción de algunos actores no deseados, no ha lugar a que se lleve a cabo en detrimento del poder real. A este respecto el soberano dirá:

"No se trata de sucumbir a un liberalismo ciego, basta con ver lo que ocurre en los países llamados desarrollados para darse cuenta de que es necesario un mínimo de Estado"81.

El Rey puede introducir reformas pero "sin perder la realidad del poder, reformas que no supongan una profunda redefinición de las reglas de juego existentes y que no afecten las relaciones de fuerzas que dominan"82.

Aun así las puertas a otro intento de alternancia siguen abiertas tal como confirma el Rey:

80. López Garcia (B.), Le Makhzen, la amma et l'arbitre au Maroc: Administration et société civile aux élections locales et législatives 1992-1993, A.A.N, Paris, Editions du CNRS, 1992, p. 420.

81. El Rey Hassan II, Entrevista en el periódico "Le Monde", op. cit. pp. 116-125.

82. EL Mossadeq, R., "Essai sur le jeu de consensus", Actas del Coloquio sobre Derecho y práctica en Marruecos, publicación de la Universidad Sidi Mohamed Ben Abdellah, Facultad de Ciencias jurídicas, económicas y sociales de Fès, 1994, p. 85.
"[...] no se puede aprobar el curso a toda costa. O bien, como he explicado, soy el profesor que no me ha expresado mal, o son los que me han escuchado quienes han entendido mal. No quiero zanjar esta cuestión. Tal vez me haya explicado mal, tal vez mi pedagogía no se haya llevado. Bien, hay que empezar de nuevo"83-84.

\subsection{Triunfo de la concepción regia}

En la calle marroquí las demandas de cambio $^{85}$ son más exigentes. Las decepciones sucesivas han engendrado "una toma de conciencia aguda y frustraciones múltiples de la juventud que sufre de lleno las consecuencias de una situación socioeconómica muy crítica" 86 . El modo de funcionamiento de las instituciones fa-

83. Véase, "La charte d'honneur» firmada por el Ministerio del Interior y los partidos políticos.

84. El Rey Hassan II, Entrevista en TV5 Europe, el 17 de septiembre 1995, in Discursos y entrevistas, op.cit., marzo 1995 - marzo 1996, Rabat, 1996, p. 201.

85. Los resultados de las elecciones dan fe de una paradoja a la altura del enigma marroquí. La obligación del cambio es un hecho. Sin embargo, sólo el $13 \%$ de los electores votaron por el koutla del que se presume encarnar la esperanza y el cambio. El primer partido de esta coalición, a saber, el U.S.F.O. reunió sólo el $6 \%$ de los votos que le aseguró el primer puesto con 57 escaños. Con estos resultados insignificantes, y en unas elecciones en las cuales dos terceras partes de los marroquíes se sintieron no concernidos, nos preguntamos si las instituciones que dependen de este panorama son verdaderamente representativas. ¿No sería allí un mensaje lleno de connotaciones, que demuestra que la población está en busca de verdaderas reformas, de verdaderos proyectos de sociedad y de una nueva formación política?

86. Jamal Khalid, "Les difficultés de la constitution d'une démocratie", La vie économique, Casablanca, novembre 1995, p. 15. 


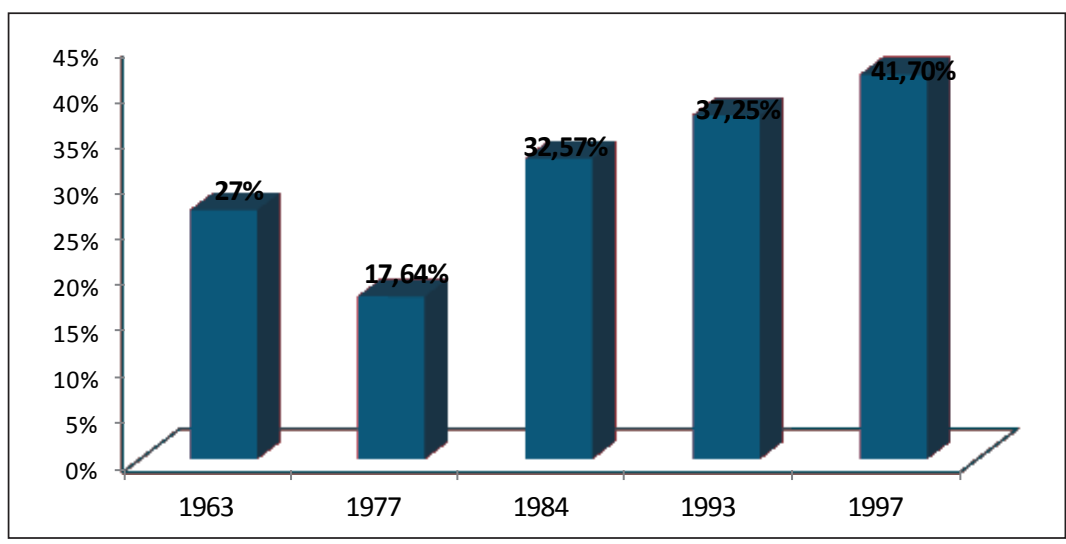

Esquema representativo del aumento de las abstenciones en las elecciones legislativas (fuente: Ministerio del Interior).

vorece la marginación. El número de abstenciones sigue aumentando desde 1977, tal como lo demuestra el gráfico.

Una situación que califica al Sr. Rousset de peligrosa y lamentable, ya que "no permite una mejor utilización de los recursos para la integración política de una facción importante del cuerpo social que identifica más con aquellos que están excluidos del poder que con los que lo ejercen desde hace muchos años"87. Este desinterés, que puede desembocar en la ilegalidad ${ }^{88}$, que podría tener consecuencias nefastas tanto sobre la democracia como sobre el poder. La sabiduría, por no decir la táctica política, requiere la implicación de un actor destacado, eso es de los partidos del Movimiento Nacional.

Como acaba de prometer, (bueno, habrá que empezar de nuevo), el soberano empieza organizando elecciones anticipadas. Según los resultados de estas eleccio-

87. Rousset, M., "Maroc 1972-1992, une constitution immuable ou changeante ?", MaghrebMachrek, ${ }^{\circ}$ 137, Paris, Juillet-Septembre 1992, p. 20.

88. Waterbury. J., "Et si le Maroc devenait la Suède ?", Le partenaire, $\mathrm{n}^{\circ}$ 25/26 du 20/01 au 19/02, 1997, p. 16 y ss. nes legislativas, ninguna familia política pudo obtener la mayoría de 163 escaños. De hecho, la koutla sólo consiguió 102 escaños. En cuanto al wifaq y el "centro", han obtenido un resultado de 97 y 100 escaños respectivamente ${ }^{89}$.

En el mismo sentido, y para remediar este impasse político, y convencer a los partidos del Movimiento Nacional para adherirse a su concepción de democracia, incluso su filosofía política, el difunto Rey, S.M. Hassan II, opta tanto por un nuevo método como por un nuevo discurso. Hace hincapié en el aspecto religioso. Estos partidos que, por su parte, insisten en la alternancia, tal como viene propuesta y presentada por el soberano, debe ser sólo un medio de transición hacia la alternancia democrática, necesaria para la realización de una vida constitucional e institucional normal, terminan por comprender que sus acciones, demandas e incluso su militancia deben tener en cuenta, en

89. Los demás partidos obtuvieron los siguientes resultados: M.P.D.C. (islamistas) 9 escaños, F.F.D.: 9 escaños (nace de una escisión en el seno del P.P.S. justo antes de las elecciones legislativas de 1997), P.S.D.: 5 escaños, P.A.: 2 escaños et P.C.I.: 1 escaño. 
términos absolutos, el particularismo marroquí en todos los ámbitos: alternancia, Constitución, sentido de la oposición etc. En resumen, deben tener en cuenta la excepción marroquí relativa a la noción de democracia.

El objetivo de este particularismo es doble: por una parte, conservar la simbiosis entre el Rey y el pueblo, y por otra, admitir que en Marruecos, el Rey debe reinar y gobernar. Para ello, el Soberano declara el 02 de septiembre de 1992:

"El Islam me prohibiría establecer una monarquía constitucional en la que el Soberano reinaría sin gobernar" 90 .

Para realizar esta noción de poder y este modo de gobierno, el soberano utiliza la tradición. Ésta le permite dar las respuestas necesarias y los argumentos adecuados para resolver los problemas planteados. Por ejemplo, la alternancia entre otros.

Para lograr la simbiosis en cuestión y salvaguardar la unidad del cuerpo marroquí, el soberano utiliza el concepto del consenso. En su discurso del 20 de agosto de 1996, el Soberano dirá:

"Para la adopción de esta ley (electoral) no se puede tener en cuenta a la mayoría o a la minoría, el grupo formado por el gobierno o la oposición. Los partidos políticos en el Parlamento y todos los grupos parlamentarios, todos ellos -estoy convencido de ello- tienen el mismo sentido de patriotismo y deben mostrar un espíritu de diálogo y adoptar una actitud positiva para dotar al país de una nueva ley electoral que tenga en cuenta la realidad marroquí y la mentalidad de los marroquíes. No debe haber en este

90. Hassan II, Entrevista en el periódico "Le Monde" el 02/09/1992, en Discursos y entrevistas de S.M. Hassan II, Ministerio de la Información, 1992/1993, Rabat, pp. 116-125. punto ni mayoría ni minoría, sino un grupo de representantes que debata para alcanzar un consenso que les honra y que honra a Marruecos"91.

Este empleo del factor religioso, que se inscribe en la línea directriz de la filosofía política del Rey Hassan II encuentra, desde la segunda mitad de los años ochenta su esencia y su espíritu en estos dos términos erigidos en cultura: "consenso» y «diálogo». A este respecto el Rey dirá:

"Y gracias a Dios, tan pronto como se inició el debate, lo que al principio parecía un simple enfoque no tardó en transformarse ante nuestros ojos en cultura, en tanto que en la actualidad el "diálogo" y el "consenso" se ha convertido en términos comunes en el léxico político nacional”92.

Esta cultura confiere a los instrumentos de la democracia un sentido propio al particularismo marroquí y a la coyuntura sociopolítica que Marruecos atraviesa.

El resultado numérico, fuente de toda legitimidad democrática, ya no es de recibo. Los principios de mayoría y de minoría ceden paso al "diálogo" y al "consenso", sinónimos de la búsqueda colectiva de la razón y de la opinión justa bajo el ojo vigilante del Rey-árbitro. Este último es, por excelencia, la institución más capaz de examinar las diferentes situaciones presentadas y de poder administrarles los remedios adecuados y no forzosamente necesarios. En este sentido, el Soberano dirá:

"No se trata de considerar la alternancia como una necesidad, pero hay que tener en cuenta la continuidad teniendo en cuenta un umbral mínimo de datos, para no ser de los que, por espíritu de venganza, borran de

91. El Rey Hassan II, Discurso del 20 de agosto 1996.

92. El Rey Hassan II, Discurso del Trono, 3 marzo de 1997. 
todo lo que han hecho sus predecesores... hacen tabla rasa de lo que se hizo antes de ellos, hundiendo así al pueblo en la confusión y la perplejidad"93.

En efecto, en Marruecos la alternancia debe tener en cuenta la continuidad de los principios fundadores del patrimonio histórico-cultural y de la filosofía política que el soberano no ha dejado en ningún momento de inculcar a los diferentes protagonistas de la vida sociopolítica marroquí: en Marruecos, el monarca reina y gobierna.

El predominio del consenso y del diálogo en detrimento de la ventaja numérica, piedra angular del espíritu democrático, y la supremacía indiscutible de la Constitución implícita sobre la constitución explícita, plebiscitada por todos los actores de la vida sociopolítica marroquí en los años noventa, marca el final de un recorrido de combatiente dirigido por el Rey con el fin de elevar su visión e incluso su filosofía política en dogma. Es el comienzo de un nuevo período en el que la divergencia y la diversidad ceden su lugar a la unanimidad y a la unidad alrededor de la razón y del interés colectivo. El Rey dirá:

"La virtud patriótica y el devenir de la patria exigen que la próxima ley electoral sea adoptada por consenso"94.

El Rey ha conseguido con éxito traer a todos los protagonistas de la vida sociopolítica marroquí a su terreno. Un terreno que únicamente el soberano domina perfectamente.

La forma en que el Gobierno del señor el Youssefi es por excelencia la prueba del éxito, por fin, de esta cultura que el difun-

93. Discurso del Rey Hassan en la sesión de apertura del Parlamento, octubre 1996.

94. E1 Rey Hassan II, Discurso del 20 de agosto 1996. to Rey no ha dejado de inculcar a la elite política marroquí a lo largo de su reinado.

Consenso, simbiosis, diálogo, unidad, etc., principios y conceptos que los ciudadanos marroquíes, todas las clases, todas las tendencias políticas, sociales, económicas, culturales, etc., deben comprender y asimilar sus dimensiones con el fin de permanecer todos unidos detrás del nuevo Rey Mohammed VI y de apoyarlo para atravesar el periodo de transición permitiéndole asentar su poder en las mejores condiciones y de consolidar la obra democrática iniciada por su padre el difunto Hassan II. Así se habría entendido el mensaje que el difunto soberano quería transmitirnos a través la alternancia (gobierno de izquierdas) y por la presencia, por primera vez, de los islamistas en la primera cámara: concretizar el consenso para superar nuestras diferencias y encontrar todos juntos (todos los protagonistas de la vida sociopolítica marroquí) las soluciones adecuadas a los problemas planteados sin renegar en ningún momento de nuestra cultura y nuestras raíces. Es decir, abrazar la modernidad sin renegar de los elementos fundadores de nuestra identidad, en particular el Islam. El difunto Rey, S.M. Hassan II dirá:

"El día en que uno de nuestros sucesores falte el respeto a nuestra identidad, la historia lo tachará inmediatamente de felón, porque habría traicionado el Derecho musulmán"95.

95. Hassan II, in "Le Point», $\mathrm{n}^{\circ}$ 1064, Rabat, 6-13/02/1993. 